\title{
Enhance the heating rate of the PECS process by inserting a conducting body into BN powder compact
}

\author{
D. ZHANG, L. ZHANG, Z. FU, J. K. GUO \\ State Key Laboratory of Advanced Technology for Materials Synthesis and Processing, Wuhan University \\ of Technology, Wuhan 430070, P. R. China
}

W. H. TUAN*

Department of Materials Science and Engineering, National Taiwan University, Taipei (106), Taiwan

E-mail: tuan@ccms.ntu.edu.tw

Pulsed electric current sintering (PECS), or the so-called spark plasma sintering (SPS), is a novel sintering process with the characteristic of short firing cycle. The process can be applied to densify metallic or ceramic bodies within a matter of minutes instead of several hours. The process is similar to the conventional hot pressing in the way that the powder compact is heated with the application of an external load. Nevertheless, instead of using an external heating source, a pulsed electric current is passed directly through the electrically conducting, such as graphite, mold.

Tokita et al. claimed that the pulsed current generates spark discharge and even plasma between conducting particles [1]. They suggested that the generation of spark discharge or plasma removes the adsorbed species from the surfaces of particles during the initial stage of PECS. The grain boundary diffusion is thus enhanced in the later stage of the process. However, Wang et al. [2] claimed that the pulsed electric current sintering on alumina is similar to that of hot-pressing. The pulsed electric current heated the graphite mold first by Jouel heat, then the heat transferred inside into the powder compact. As the heating rate is fast, a temperature gradient exists. A dense outer region is thus observed within an alumina specimen after PECS [2]. Munir et al. suggested that the presence of pulsed electric field contributes to the fast densification [3]. Shen et al. suggested that the discharge can still take place between the non-conducting particles [4].

Many attempts have been made to explore the sintering mechanism of PECS. Though systematic studies have been conducted [1-5], the mechanisms for the densification and grain growth are far from clear. Nevertheless, most previous studies agreed upon the significance of PECS technique to the industrial production. In the present study, the presence of spark discharge between conducting particles is confirmed by inserting a conducting body into nonconducting particles.

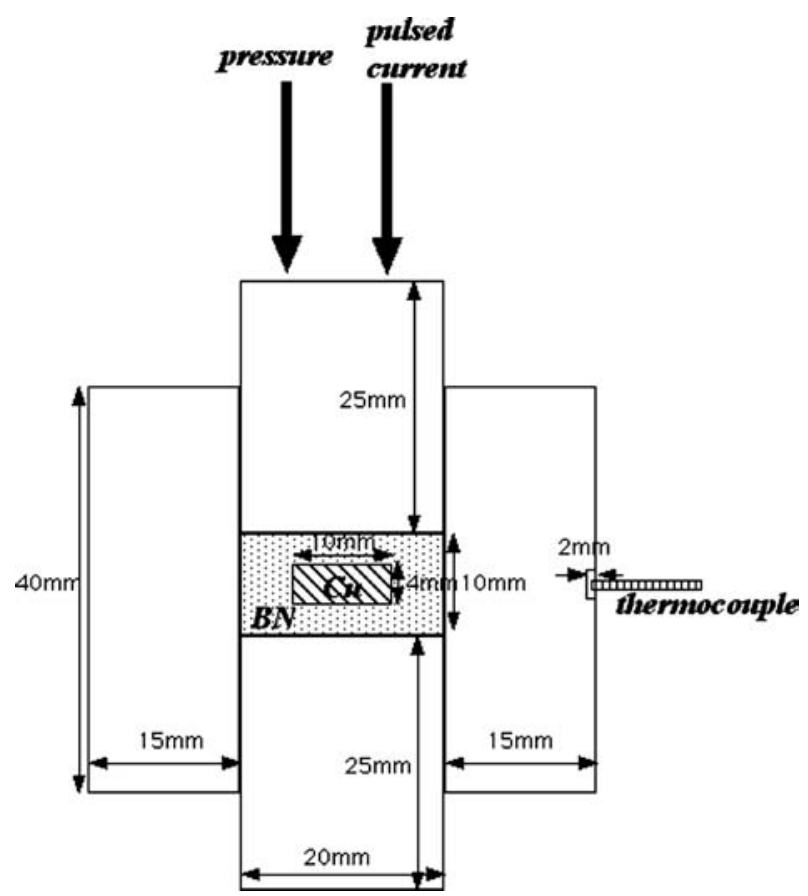

Figure 1 Schematic of the experimental setup for the PECS process.

Several copper specimens were prepared by using a PECS furnace (Model SPS-1050, Sumitomo Coal Mining Co., Tokyo, Japan). The $\mathrm{Cu}$ particles with average size of $20-30 \mu \mathrm{m}$ were packed in a WC-Co die with an inner diameter of $10 \mathrm{~mm}$. The punches were also made of WC-Co. An external pressure of $100 \mathrm{MPa}$ was applied uniaxially on the powder compact throughout the PECS process. The peak temperature was $400{ }^{\circ} \mathrm{C}$. The heating rate was $100^{\circ} \mathrm{C} / \mathrm{min}$ and the dwell time $1 \mathrm{~min}$. The final dimensions of the $\mathrm{Cu}$ specimen were $4 \mathrm{~mm}$ in thickness and $10 \mathrm{~mm}$ in diameter. The $\mathrm{Cu}$ specimens were nearly fully dense after PECS.

\footnotetext{
* Author to whom all correspondence should be addressed.
} 


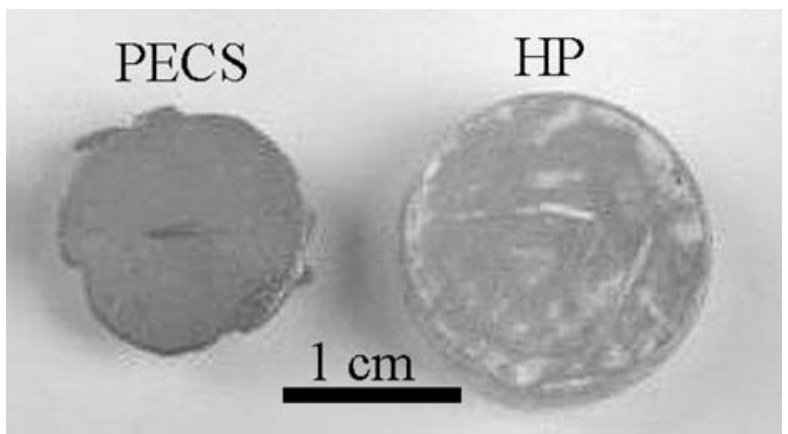

Figure 2 Morphology of the $\mathrm{Cu}$ specimen after removing the surrounding $\mathrm{BN}$.

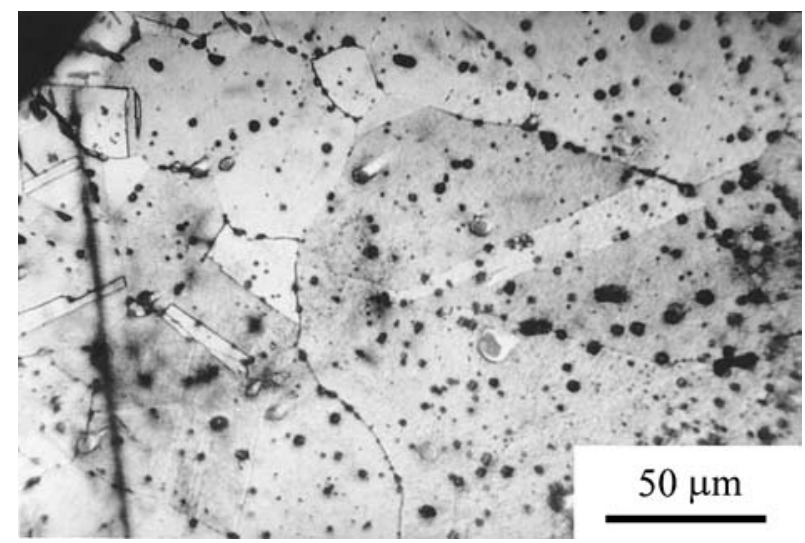

Figure 3 Microstructure of the $\mathrm{Cu}$ specimen after $\mathrm{HP}$ at $1080^{\circ} \mathrm{C}$ for $1 \mathrm{hr}$.

The $\mathrm{Cu}$ specimen was then inserted into the center of a boron nitride powder compact, as shown in the schematic in Fig. 1. A graphite mold with outer diameter of $50 \mathrm{~mm}$ and inner diameter of $20 \mathrm{~mm}$ was used during PECS. The load applied was $30 \mathrm{MPa}$. The peak temperature was $1080{ }^{\circ} \mathrm{C}$, the dwell time $1 \mathrm{~min}$. The temperature was measured by using a $K$-type thermo-couple that inserted into a hole on the outer surface of the mold. The depth of the hole was $2 \mathrm{~mm}$. The final thickness of the specimen was $10 \mathrm{~mm}$.
A comparison experiment was also conducted by using a hot-pressing technique. The $\mathrm{Cu}$ specimen prepared by PECS was also inserted into a $\mathrm{BN}$ powder compact, then hot-pressed at $1080^{\circ} \mathrm{C}$ with a load of $30 \mathrm{MPa}$. A graphite mold with the same dimensions as those of the PECS mold was also used; the dwell time at hot-pressing was $1 \mathrm{hr}$.

The BN was not fully dense after either PECS or HP treatments. The $\mathrm{Cu}$ specimen could be easily removed from the $\mathrm{BN}$ powder compact. The cross-section of the $\mathrm{Cu}$ specimen was polished and etched in $10 \% \mathrm{HCl}$ solution, then observed with an optical microscope.

The morphology of the $\mathrm{Cu}$ specimen after PECS and $\mathrm{HP}$ is shown in Fig. 2. The $\mathrm{Cu}$ specimen after HP remains its original shape and size. However, a serious shape distortion is noted for the $\mathrm{Cu}$ specimens after PECS treatment. Furthermore, the size of the PECS specimen is much smaller than that of the HP specimen. Many small copper droplets are noted on the inner surface of the graphite mold, especially at the gap between punch and mold. It indicates that the temperature of $\mathrm{Cu}$ specimen during PECS treatment is far higher than the temperature measured from the outer surface of the graphite mold. The temperature is not only higher than the melting point of $\mathrm{Cu}$ but also high enough to vaporize some $\mathrm{Cu}$.

The cross-section of the $\mathrm{Cu}$ specimens after HP and PECS is shown in Figs 3 and 4, respectively. Though the dwell time at the peak temperature during PECS is much shorter than that at the HP temperature, the grain size of the $\mathrm{Cu}$ specimen treated with PECS is much larger than that of the specimen treated with HP. It implies that either the temperature of the conducting $\mathrm{Cu}$ specimen or the grain growth rate is increased significantly by using BN powder surrounding. There are many debates on the coarsening behavior during PECS process. Systematic studies had been conducted [1-5]; these studies recognized the importance of controlling the processing parameters during PECS. Among the processing parameters, the peak temperature, pressure and heating rate are found to be the three most influential

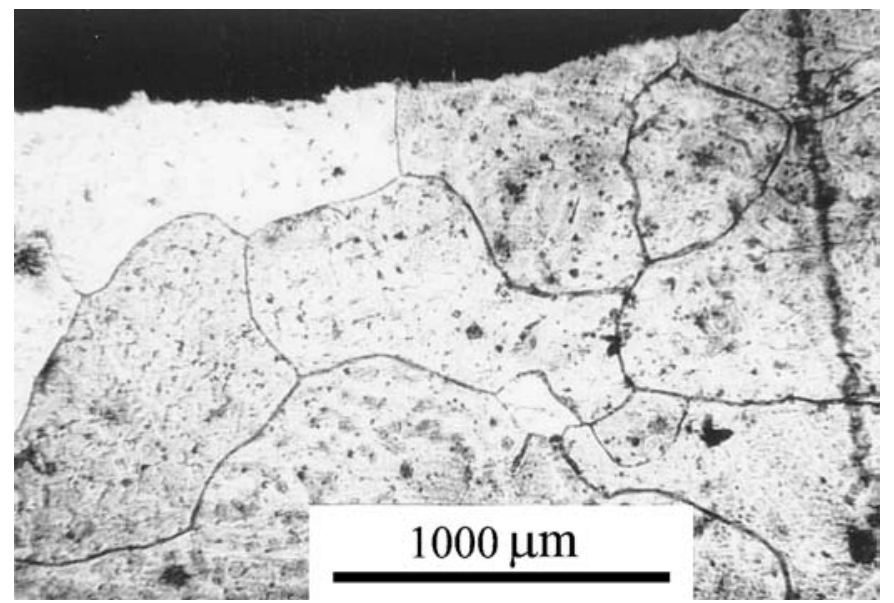

Figure 4 Microstructure of the $\mathrm{Cu}$ specimen after PECS at $1080{ }^{\circ} \mathrm{C}$ for $1 \mathrm{~min}$. 
parameters. Raising the peak temperature and pressure during PECS can usually increase the final grain size. Nevertheless, the role of heating rate on coarsening behavior remains unclear. The increase of heating rate has been reported to result in finer grain size [2, 4, 6-8]. However, a fast heating rate has also been reported as the key parameter to enhance grain growth [5]. A recent study proposed that the coarsening behavior during PECS is far more complicate than one would expect [9]. Zhou et al. indicated that higher heating rate induces higher coarsening rate at the early stage and a lower rate at late stage of sintering. In any case, since the shape of the $\mathrm{Cu}$ specimen after PECS is distorted and the existence of $\mathrm{Cu}$ drops at the gap between punch and mold, it indicates that the temperature of the $\mathrm{Cu}$ specimen during PECS is much higher than that of the graphite mold. The coarsening of the $\mathrm{Cu}$ specimen prepared by PECS process is likely contributed mainly by the resulting high temperature. A separate experiment has also been conducted by inserting titanium diboride $\left(\mathrm{TiB}_{2}\right)$ powder compact into the $\mathrm{BN}$ powder bed. A sharp temperature increase has also been observed for the $\mathrm{TiB}_{2}$ specimen [10]. Though the $\mathrm{Cu}$ specimen was not in contact with the graphite mold during PECS and the time at the peak temperature during PECS was very short, $1 \mathrm{~min}$, the temperature and heating rate on the embedded $\mathrm{Cu}$ specimen are significantly increased. BN is an electrical insulator; the presence of BN powder bed should affect little on the electrical field around the $\mathrm{Cu}$ specimen. Therefore, the pulsed electric current can still induce spark discharge between $\mathrm{Cu}$ particles. It implies that the spark discharge is the dominant mechanism for the increase of heating rate. Furthermore, BN is also a good thermal insulator; the heat generated within the $\mathrm{Cu}$ powder compact by the spark discharge is confined within the porous BN powder bed. Therefore, the temperature of the $\mathrm{Cu}$ specimen is high. A recent study demonstrated that the addition of 1 vol.\% Ni nanoparticles could enhance the grain growth of alumina matrix during PECS [11]. It also suggested that the incorporation of conducting particles into nonconducting powder compact could introduce an extra heating mechanism into the non-conducting specimen.

The heating rate during pulsed electric current sintering (PECS) is very fast, $>100^{\circ} \mathrm{C} / \mathrm{min}$. In the present study, a methodology is introduced to further enhance the heating rate. An electrical conducting body, $\mathrm{Cu}$ specimen, was inserted into a non-conducting $\mathrm{BN}$ powder compact; both the heating rate and peak temperature on the $\mathrm{Cu}$ specimen are consequently increased. The increase of heating rate is related to the presence of spark discharge within the conducting particles.

\section{References}

1. M. TOKITA, Mater. Sci. Forum 83 (1999) 308.

2. S. W. WANG, L. D. CHEN and T. HIRAI, J. Mater. Res. 15 (2000) 982.

3. J. W. LEE, Z. A. MUNIR, M. SHIBUYA and M. OHYANAGi, J. Amer. Ceram. Soc. 84 (2001) 1209.

4. Z. SHEN, M. JOHNSSON, Z. ZHAO and M. NYGREN, ibid. 85 (2002) 1921.

5. Z. SHEN Z. ZHAO, H. PENG and M. NYGREN, Nature 417 (2002) 266.

6. D. D. JAYASEELAN, N. KONDO, D. A. RANi, S. UENO, T. OHJi and S. KANZAKI, J. Amer. Ceram. Soc. 85 (2002) 2870 .

7. S. W. WANG, L. D. CHEN, T. HIRAI and J. GUO, J.Mater. Res. 16 (12)(2001) 3514.

8. D. D. JAYASEELAN, S. UENO, T. OHJI and S. KANZAKI, J. Am. Ceram. Soc. 87 (2004) 159.

9. Y. ZHOU, K. HIRAO, Y. YAMAUCHI and S. KANZAKI, $J$. Euro. Ceram. Soc. 24 (2004) 3465.

10. D. ZHANG, L. ZHANG and W. H. TUAN, in preparation.

11. W. H. TUAN, S. M. LIU, C. J. HO, C. S. LIN, T. J. YANG, D. M. ZHANG, Z. Y. FU and J. K. GUO, J. Euro. Ceram. Soc. (in print).

12. L. GAO, H. Z. WANG, J. S. HONG, H. MiYAmOto, K. MIYAMOTO, Y. NISHIKAWA, and S. D. D. L. TORRE, ibid. 19 (1999) 609.

Received 3 January

and accepted 17 June 2005 